\title{
Effect of chemotherapy, vaccines and immunostimulants on innate immunity of goldfish infected with Aeromonas hydrophila
}

\author{
Ramasamy Harikrishnan ${ }^{1}$, Chellam Balasundaram ${ }^{2}$, Moon-Soo Heo ${ }^{1, *}$ \\ ${ }^{1}$ Marine Applied Microbes \& Aquatic Organism Disease Control Lab, Department of Aquatic Biomedical Sciences, \\ School of Marine Biomedicals Sciences, College of Ocean Science \& Marine and Environmental Research Institute, \\ Jeju National University, Jeju 690 756, South Korea \\ ${ }^{2}$ Department of Animal Science, Bharathidasan University, Tiruchirapalli 620 024, Tamilnadu, India
}

\begin{abstract}
We report the effect of various chemicals, vaccines and immunostimulants on innate immune mechanisms such as phagocytosis activity, superoxide anion production of blood leukocytes, complement activity and plasma lysozyme activity and disease resistance in goldfish Carassius auratus $(23 \pm 2 \mathrm{~g})$ against Aeromonas hydrophila on Days 15 and 30 post-infection. In infected fish, the administration of diets supplemented with either probiotics, tri-herbal extract or azadirachtin for $30 \mathrm{~d}$ significantly enhanced phagocytic activity; administration for $15 \mathrm{~d}$ had no effect. In fish treated with heat-killed and formalin-killed vaccines, and probiotics-, tri-herbal- and azadirachtin-supplemented diets, superoxide anion production was enhanced on Day 30. However, there was no superoxide anion production in fish treated with tetracycline, furanace, formalin or hydrogen peroxide. Complement activity was also significantly enhanced on Days 15 and 30 in fish groups treated with vaccine and probiotics-, tri-herbal- and azadirachtin-supplemented diets. Other groups had no complement activity. Lysozyme activity was significantly enhanced after $30 \mathrm{~d}$ in fish treated with heat-killed vaccine and probiotics-, tri-herbal- and azadirachtin-supplemented diets. The probiotics- and tri-herbalcontaining diet administration groups had no mortality $(0 \%)$ preceding the challenge with live A. hydrophila. Groups treated with heat- or formalin-killed vaccines or azadirachtin-supplemented diet suffered mortalities of 30, 35 and $10 \%$, respectively, which represents an improvement of survival rate compared to untreated infected control groups. We conclude that probiotics-, tri-herbaland azadirachtin-supplemented diets act as immunostimulants enhancing the goldfish innate immune response and disease resistance against A. hydrophila.
\end{abstract}

KEY WORDS: Nonspecific immune parameter · Carassius auratus • Aeromonas hydrophila . Tri-herbal $\cdot$ Probiotic $\cdot$ Azadirachtin

Resale or republication not permitted without written consent of the publisher

\section{INTRODUCTION}

Ornamental fish-keeping has increased around the world, with a wide range of ornamental fish species imported from countries such as Singapore, China, South Africa and the USA. While goldfish Carassius auratus (L.) is the most common fish kept in garden ponds and cold-water aquaria, varieties such as koi carp fetch more lucrative prices in the global ornamental-fish trade. Aeromonas hydrophila is one of various pathogens that affect wild and cultured fish. A. hydrophila is a ubiquitous, opportunistic Gram-negative and heterogeneous bacterial pathogen that produces motile aeromonad septicaemia associated with the common symptoms of haemorrhagic septicaemia, exophthalmia and abdominal distension, especially under stress conditions (Harikrishnan et al. 2009a). In warmwater and cold-water aquaculture, A. hydrophila infection is considered to be a major economic problem, inflicting severe loss on fish production in Southeast Asia 
(Areerat 1987) and other regions of the world (Amin et al. 1985). A. hydrophila routinely isolated from healthy and moribund fish produce cytotoxins, proteases, surface (S)-layers and aerolysin toxins (Cahill 1990, Paniagua et al. 1990, Rahman et al. 1997).

Aeromonas hydrophila infection can be controlled with antibiotics and chemicals. Traditional use of oral antibiotics such as oxytetracycline, chloramphenicol and nifurpirinol remains the most convenient form of therapy for motile aeromonad septicaemia (Noga 1996). However, antibiotic treatment is costprohibitive to farmers in many undeveloped and developing countries. Extensive use of antibiotics may result in residues (Shao 2001) and an increase in multidrug-resistant bacteria in human and veterinary medicine (Bryan 1984). Therefore, vaccination is a better choice to control A. hydrophila infections. At present, no vaccines for the protection of farmed fish against A. hydrophila infections are commercially available (Karunasagar et al. 1997). As an alternative, pathogenspecific vaccines have been used with varying degrees of success. The wide range of pathogens limits the effectiveness of vaccines (Harikrishnan et al. 2003). Hence, there is an urgent need to look for eco-friendly disease-preventative measures to promote sustainable ornamental-fish culture. India is endowed with a rich wealth of medicinal plants. Prevention and treatment of infectious diseases by applying plant-derived products is a possible alternative. Hence the use of plant compounds as a potential and promising source of pharmaceutical agents is gaining momentum (Mayer \& Hamann 2002, Newman et al. 2003). Many plants have been used in disease prevention by incorporation into fish feeds; in China about 10 herbs are commonly used to treat diseases like enteritis, gill rot, white head and white mouth disease (Rath 2000). This herbal immunoregulation mixture comprises several traditional Chinese medicines that can be effectively used as immunomodulators (Tzianabos 2000, Jian \& Wu 2003).

Azadirachtin is known to enhance disease resistance by promoting specific and nonspecific defence mechanisms in fish (Mitra et al. 1971, Rojanapo et al. 1985, Tzianabos 2000). Azadirachtin is a possible future drug that could be used as an immunostimulant or an adjuvant in vaccination; it can stimulate and enhance primary and secondary immune responses in fishes such as tilapia Oreochromis mossambicus (Logambal \& Michael 2001). Harikrishnan \& Balasundaram (2005) and Harikrishnan et al. (2005, 2009b) examined the antibacterial activity against Aeromonas hydrophila of an aqueous herbal concoction of Azadirachta indica, Ocimum sanctum and Curcuma longa and the resulting enhanced innate immune response in host fish. The present study evaluated innate immune mechanisms such as phagocytosis activity, superoxide anion production of blood leukocytes, complement activity and plasma lysozyme activity and disease resistance in goldfish against Aeromonas hydrophila after administration of antibiotics, chemicals, vaccines or immunostimulant-enriched diets.

\section{MATERIALS AND METHODS}

Fish. Goldfish Carassius auratus (mean \pm SD body weight, $23 \pm 2$ g; $\mathrm{n}=1200$ ) were obtained from an ornamental-fish farm in Tiruchirapalli, Tamilnadu, India $\left(10^{\circ} 48^{\prime} \mathrm{N}, 78^{\circ} 41^{\prime} \mathrm{E}\right)$ in March 2006. Fish were transported alive in plastic bags containing water enriched with oxygen. They were acclimated for $2 \mathrm{wk}$ in glass aquaria $(100 \times 60 \times 40 \mathrm{~cm})$ filled with chlorine-free tap water and provided with continuous aeration using electric air-pumping compressors; $50 \%$ of the water was exchanged twice a week to remove waste feed and faecal materials. During the experiment, water temperature was $20 \pm 2{ }^{\circ} \mathrm{C}, \mathrm{pH} 6.91 \pm 1.44$, salinity $0.25 \pm 0.05 \mathrm{mg} \mathrm{l}^{-1}$, dissolved oxygen concentration $6.63 \pm 1.00 \mathrm{mg}^{-1}$ and the photoperiod was a $14 \mathrm{~h}$ light: $10 \mathrm{~h}$ dark cycle. Prior to the experiment, fish were fed a standard diet ad libitum twice a day at 09:00 and $15: 00 \mathrm{~h}$ at a rate of $3 \%$ of their body weight.

Bacterial strain and growth conditions. Aeromonas hydrophila (strain MTCC 646) was obtained from the Institute of Microbial Technology, Government of India, Chandigarh, and maintained in the laboratory under standard conditions (Harikrishnan et al. 2003). Subcultures were maintained on tryptone soya agar (TSA, Himedia) in slopes at $5^{\circ} \mathrm{C}$ and routinely tested for pathogenesis (Joseph \& Carnahan 1994) by inoculation into goldfish through intramuscular injection (Davis \& Hayasaka 1983). A stock culture in tryptone soya broth (TSB, Himedia) was stored at $-70^{\circ} \mathrm{C}$ with $0.85 \%(\mathrm{w} / \mathrm{v}) \mathrm{NaCl}$ and $20 \%$ (v/v) glycerol to provide stable inocula throughout the present study (Chabot \& Thunne 1991, Yadav et al. 1992). A. hydrophila subcultures were prepared according to the method in Harikrishnan et al. (2003). The culture was centrifuged at $1000 \times g$ for $10 \mathrm{~min}$ at $-4^{\circ} \mathrm{C}$. The supernatant was discarded and the bacterial pellet was washed 3 times and resuspended in phosphate-buffered saline (PBS) at pH 7.2 (Harikrishnan et al. 2003). The optical density (OD) of the solution was adjusted to 0.5 at $456 \mathrm{~nm}$, which corresponded to $1 \times 10^{7}$ cells $\mathrm{ml}^{-1}$.

Chemicals. The chemical treatments were a daily bath in 200 ppm of formalin (Marine Depot) (Jung et al. 2003) or 200 ppm of hydrogen peroxide (Russo et al. 2007 ) in a daily bath or dip treatment for $10 \mathrm{~min}$ after challenge with live Aeromonas hydrophila.

Vaccines and vaccination. Aeromonas hydrophila cultures grown in bulk were harvested by centrifuga- 
tion at $10000 \times g$ for $10 \mathrm{~min}$ at $4^{\circ} \mathrm{C}$. The bacterial pellet was washed twice and resuspended in PBS ( $\mathrm{pH} 7.2$ ). The heat-killed $A$. hydrophila $\left(2.3 \times 10^{5}\right.$ colony-forming units $[\mathrm{CFU}] \mathrm{ml}^{-1}$ ) vaccine was prepared by heatkilling at $60^{\circ} \mathrm{C}$ for $1 \mathrm{~h}$ in a water bath and was stored at $-20^{\circ} \mathrm{C}$ (Azad et al. 1999). To prepare formalin-killed A. hydrophila $\left(2.3 \times 10^{5} \mathrm{CFU} \mathrm{m}^{-1}\right)$ vaccine, whole cell antigens were washed and killed in a $0.4 \%$ formalinPBS solution at $4^{\circ} \mathrm{C}$ overnight (Chu 2006). There were 50 fish in each vaccine group. Fish were injected with vaccine at Week 0 followed by a booster at Week 3 . After 3 wk, vaccine-treated fish were used for the challenge study.

Tri-herbal extract. Leaves from Azadirachta indica, Ocimum sanctum and Curcuma longa were collected from the Bharathidasan University campus in March 2006. The leaves were collected and washed in sterile distilled water. They were shade-dried, powdered and stored at $-20^{\circ} \mathrm{C}$ until further use. The extraction was done following the methods of Harikrishnan \& Balasundaram (2005). Ten grams of each leaf powder to mix equal quantities of the powders (w/w) were evenly mixed (1:1:1) and placed into sterilised $100 \mathrm{ml}$ conical flasks with $100 \mathrm{ml}$ of solvent (ethanol) and mixed well. The flasks were tightly covered with aluminium foil, kept for $7 \mathrm{~d}$ at room temperature and agitated daily to ensure complete digestion. The extract was then filtered through sterile muslin cloth. The filtrate was collected and the solvent was evaporated using a rotary vacuum evaporator (Buchi SMP). The residue obtained after evaporation was mixed with sterile ethanol separately at $0.25 \%(\mathrm{w} / \mathrm{v})$ in a sterilised screw-cap glass container for further use.

Probiotic bacteria. The probiotic bacterial strain of Lactobacillus rhamnosus was obtained from Inter care (Mehsana, Gujarat) (Ahilan et al. 2004). The bacterium was cultured in MRS broth (De Man et al. 1960) by cultivating for $48 \mathrm{~h}$ at $30^{\circ} \mathrm{C}$ and subsequently preserved in $50 \%$ glycerol at $-80^{\circ} \mathrm{C}$ and kept as stab culture for further use. A pure colony was taken for inoculation of seed cultures of $50 \mathrm{ml}$ each and incubated at $30^{\circ} \mathrm{C}$ for $24 \mathrm{~h}$ before mass culture in MRS broth. After $1 \mathrm{~d}$ of culturing, bacteria were harvested by centrifuging at $16500 \times g$ for $10 \mathrm{~min}$ and washing 3 times with sterile peptone water $(0.85 \% \mathrm{NaCl}$ and $0.1 \%$ polypeptone).

Standard diet and 5 supplemented diets. The formulated fish feed was prepared in the laboratory using soybean and fish meal as the protein sources. The prepared standard feed $(\mathrm{g} / \mathrm{kg})$ was composed of $18 \%$ fish meal, $18 \%$ groundnut oil cake, $16 \%$ sesame oil cake, $16 \%$ soya flour, $16 \%$ rice bran, $16 \%$ tapioca powder and $0.5 \%$ vitamin and mineral mix (w/v) with an approximate composition of $39 \%$ protein, $24 \%$ carbohydrate, $11 \%$ lipid and $9 \%$ ash (Table 1). To prepare the probioticsenriched diet, the required amount of bacterial suspension was sprayed into the feed slowly, mixing part by part in a drum mixer, after which it was air-dried under sterile conditions for $12 \mathrm{~h}$. The viability of the incorporated bacterial cells in the feed was assessed by spreading onto triplicate plates of TSA (Becton, Dickinson and Company), MRS agar (Merck) and blood agar (BA, Nissui). The colony count was taken after incubation at $30^{\circ} \mathrm{C}$ for $48 \mathrm{~h}$. The bacterial count of the feed was taken at this point and twice during the trial and averaged $2.45 \times 10^{9} \mathrm{CFU} \mathrm{g}^{-1}$. The pellets were dried in an oven at $30^{\circ} \mathrm{C}$ for $18 \mathrm{~h}$, packed and stored in a freezer at $-20^{\circ} \mathrm{C}$ until used. The final concentration of live Lactobacillus rhamnosus in the probiotic feed pellets before the feeding trial was $2.45 \times 10^{9} \mathrm{CFU} \mathrm{g}^{-1}$. The other 4 supplemented diets were prepared by adding tetracycline, furanace, the tri-herbal mix or azadirachtin (each at $0.25 \%$ or $2.5 \mathrm{~g} \mathrm{~kg}^{-1}$ ) to standard feed. Feeding was started after the challenge with live Aeromonas hydrophila on Day 1.

Table 1. Carassius auratus. Composition of diets for goldfish

\begin{tabular}{|c|c|c|}
\hline Component & Composition & Concentration (\%) \\
\hline \multicolumn{3}{|l|}{ Standard diet } \\
\hline Fish meal & Animal protein & 18 \\
\hline Ground nut oil cake & Plant protein & 18 \\
\hline Sesame oil cake & Plant protein & 16 \\
\hline Soya flour & Plant protein & 16 \\
\hline Rice bran & Carbohydrate & 16 \\
\hline Tapioca flour & Binder & 16 \\
\hline Vitamin $^{\mathrm{a}}$ and mineral ${ }^{\mathrm{b}}$ mix & Vitamins and minerals & 0.5 \\
\hline \multicolumn{3}{|l|}{ Additions to standard diet } \\
\hline Lactobacillus rhamnosus & Probiotic & $0.25\left(2.5 \mathrm{~g} \mathrm{~kg}^{-1}\right)$ \\
\hline Tetracycline & Antibiotic & $0.25\left(2.5 \mathrm{~g} \mathrm{~kg}^{-1}\right)$ \\
\hline Furanace & Antibiotic & $0.25\left(2.5 \mathrm{~g} \mathrm{~kg}^{-1}\right)$ \\
\hline Tri-herbal mix & Herbal extract & $0.25\left(2.5 \mathrm{~g} \mathrm{~kg}^{-1}\right)$ \\
\hline Azadirachtin & Herbal compound & $0.25\left(2.5 \mathrm{~g} \mathrm{~kg}^{-1}\right)$ \\
\hline \multicolumn{3}{|c|}{ 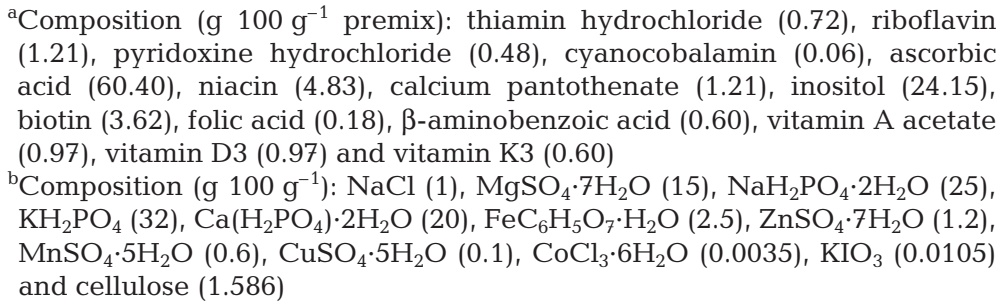 } \\
\hline
\end{tabular}


Experimental design. Goldfish in all groups except control were inoculated intramuscularly (50 $\mu \mathrm{l})$ with live Aeromonas hydrophila $\left(2.3 \times 10^{5} \mathrm{CFU} \mathrm{ml}^{-1}\right)$ using a $1 \mathrm{ml}$ tuberculin syringe with a 24 -gauge needle on Day 1. Control fish received $50 \mu \mathrm{l}$ of PBS. The 11 groups were: control (not infected) and fed standard diet; infected but untreated, and fed standard diet; infected and fed tetracycline-containing diet; infected and fed furanace-containing diet; infected, dip-treated with formalin and fed standard diet; infected, diptreated with hydrogen peroxide and fed standard diet; immunised with heat-killed vaccine and fed standard diet; immunised with formalin-killed vaccine and fed standard diet; infected and fed probiotics-enriched diet; infected and fed tri-herbal-enriched diet; and infected and fed azadirachtin-enriched diet. All groups were maintained separately in replicate tanks ( $\mathrm{n}=$ 1200). On Day 15 and Day 30 individual fish were anaesthetised with $\mathrm{MS}-222\left(\mathrm{NaHCO}_{3}\right.$ and tricaine methanesulphonate; Sigma Chemicals) 1:4000 in dechlorinated water for $2 \mathrm{~min}$.

Blood sampling and separation of leukocytes. Blood samples $(0.5 \mathrm{ml})$ were drawn via the caudal vessels, punctured using a heparin-coated needle and syringe. Blood samples (6 fish group ${ }^{-1}$ ) were collected on Days 15 and 30. Heparin was used as an anticoagulant. Individual fish were sampled only once to avoid affecting the assays with multiple bleeds and handling stress in the fish. Leukocytes for assay were separated from each blood sample by density-gradient centrifugation (Rowley 1990). One ml of Histopaque 1.119 (Sigma) containing $100 \mu \mathrm{l}$ of Bacto haemagglutination buffer at pH 7.3 (Difco) was dispensed into siliconised tubes. One $\mathrm{ml}$ of a mixture of Histopaque 1.077 and haemagglutination buffer was layered on top. One $\mathrm{ml}$ of the blood sample was then layered carefully on top of the gradient. Sample preparations were centrifuged at $700 \times g$ for $30 \mathrm{~min}$ at $4^{\circ} \mathrm{C}$. After centrifugation, plasma was collected and stored at $-20^{\circ} \mathrm{C}$ for future analysis. Separated leukocytes were gently removed and dispensed into siliconised tubes containing phenol-redfree Hanks' balanced salt solution (HBSS). Cells were then washed twice in HBSS and adjusted to $10^{7}$ viable cells $\mathrm{ml}^{-1}$.

Phagocytosis. Phagocytic activity of blood leukocytes was determined spectrophotometrically by the method of Seeley et al. (1990). This assay involves the measurement of Congo red-stained yeast cells that have been phagocytised by cells. To perform the assay, $1000 \mu \mathrm{l}$ of the leukocyte suspension was mixed with $2000 \mu \mathrm{l}$ of Congo red-stained and autoclaved yeast cell suspension (providing a yeast cell:leukocyte ratio of 20:1). The mixtures were incubated at room temperature for $60 \mathrm{~min}$. Following incubation, $1 \mathrm{ml}$ of ice-cold HBSS was added and $1 \mathrm{ml}$ of Histopaque 1.077 was injected into the bottom of each sample tube. The samples were centrifuged at $850 \times g$ for 5 min to separate leukocytes from free yeast cells. Leukocytes were harvested and washed twice in HBSS. The cells were then resuspended in $1 \mathrm{ml}$ trypsin-EDTA solution $\left(5.0 \mathrm{~g} \mathrm{l}^{-1}\right.$ trypsin and $2.0 \mathrm{~g} \mathrm{l}^{-1}$ EDTA; Sigma) and incubated at $37^{\circ} \mathrm{C}$ overnight. The absorbance of the samples was measured at $510 \mathrm{~nm}$ using trypsin-EDTA as a blank.

Superoxide anion production. The superoxide anion production $\left(\mathrm{O}_{2}^{-}\right)$of the blood leukocytes was quantified using the nitroblue tetrazolium (NBT) assay (Secombes 1990), which measures the quantity of intracellular oxidative free radicals. This method was slightly changed, as we used a concentration of NBT solution of $2 \mathrm{mg} \mathrm{ml}^{-1}$.

Alternative complement activity. Alternative complement haemolytic activity $\left(\mathrm{ACH}_{50}\right)$ was assayed following the procedure of Yano (1992), based on the haemolysis of rabbit red blood cells (RaRBC) as described in Amar et al. (2000). The volume yielding $50 \%$ haemolysis was used for determining the complement activity of the plasma sample as follows:

$$
\begin{aligned}
& \left.\mathrm{ACH}_{50} \text { value (units } \mathrm{ml}^{-1}\right)= \\
& 1 / K \times(\text { reciprocal of the serum dilution }) \times 0.5
\end{aligned}
$$

where $K$ is the amount of serum (ml) giving $50 \%$ lysis and 0.5 is the correction factor since the assay was performed at half the scale of the original method.

Lysozyme activity. Plasma lysozyme activity was measured spectrophotometrically according to the method of Ellis (1990). A $0.02 \%$ (w/v) suspension of Micrococcus lysodeikticus made up in $0.05 \mathrm{M}$ phosphate buffer (pH 6.2) was used as substrate. Lyophilised hen egg white lysozyme was used as a standard. A new standard curve was prepared for each assay. Standard solutions as well as samples were added to the substrate at $25^{\circ} \mathrm{C}$. The results were expressed as $\mu \mathrm{g} \mathrm{ml}^{-1}$ equivalent of hen egg white lysozyme activity.

Disease resistance. Aeromonas hydrophila (MTCC 646) was inoculated in TSB at $28^{\circ} \mathrm{C}$. The culture was centrifuged at $800 \times g$ for $15 \mathrm{~min}$ at $4^{\circ} \mathrm{C}$. The packed cells were washed and the required dose was prepared in PBS using a haemocytometer. From each group, 10 fish were used in duplicate. Each fish was inoculated intramuscularly $(50 \mu \mathrm{l})$ with live A. hydrophila $\left(2.3 \times 10^{5} \mathrm{CFU} \mathrm{ml} \mathrm{m}^{-1}\right)$, except control fish, which received $50 \mu \mathrm{l}$ of PBS, and except the group given the tri-herbal supplement, which were challenged with A. hydrophila $\left(1 \times 10^{7}\right.$ cells $\left.\mathrm{ml}^{-1}\right)$ intraperitoneally (50 $\mu \mathrm{l}$ ) on Day 7 . The challenge dose was standardised to give $80 \%$ mortality in the infected but untreated group. Mortality was recorded daily for $30 \mathrm{~d}$. The cause of death was confirmed by re-isolating $A$. hydrophila from liver and muscle of $15 \%$ of dead fish in Rimler-Shotts medium containing novobiocin (Shotts \& 
Rimler 1973). The relative percent survival (RPS) of each treated group was calculated using the following formula from Ellis (1988):

$$
\begin{aligned}
\text { RPS }= & 1-(\text { Percent mortality in treated group } / \\
& \text { Percent mortality in control group }) \times 100
\end{aligned}
$$

Statistics. Experimental data are presented as mean $\pm \mathrm{SE}$ and were analysed with 1-way ANOVA followed by Tukey's test to compare the means between individual treatments in SPSS at a significance level of $\mathrm{p}<$ 0.05 . activity are shown in Fig. 3. Serum complement activity, measured by the mean number of $\mathrm{ACH}_{50}$ units $\mathrm{ml}^{-1}$ serum, increased in infected fish treated with vaccines (heat-killed and formalin-killed) and immunostimulants (probiotics, tri-herbals and azadirachtin) on Days 15 and 30. Complement activity did not increase following treatment with antibiotics (tetracycline and furanace) or chemicals (formalin and hydrogen peroxide) on Day 15 or 30.

\section{Lysozyme activity}

\section{RESULTS}

\section{Phagocytosis}

On Day 30, the phagocytosis activity of blood leukocytes was significantly enhanced in the groups receiving probiotics-, tri-herbal- and azadirachtin-enriched diets (Fig. 1). However, no significant phagocytosis activity had been found in these groups on Day 15 compared to control. Treatment with antibiotics (tetracycline and furanace), chemicals (formalin and hydrogen peroxide) and vaccines (heat-killed and formalin-killed) did not enhance phagocytosis activity on Day 15 or 30 compared to control.

\section{Superoxide anion production}

The effects of the chemotherapies (tetracycline, furanace, formalin and hydrogen peroxide), vaccines (heat-killed and formalin-killed) and immunostimulant diets (probiotics, tri-herbals and azadirachtin) on the superoxide anion production of isolated blood leukocytes is shown in Fig. 2. Administration of either of the 2 vaccines or any of the 3 immunostimulant diets did not increase superoxide anion production on Day 15 but did on Day 30. There was no significant increase in superoxide anion production in the groups treated with antibiotics (tetracycline and furanace) and chemicals (formalin and hydrogen peroxide) on Day 15 or 30.

\section{Alternative complement activity}

The effects of the various treatments on plasma natural haemolytic complement

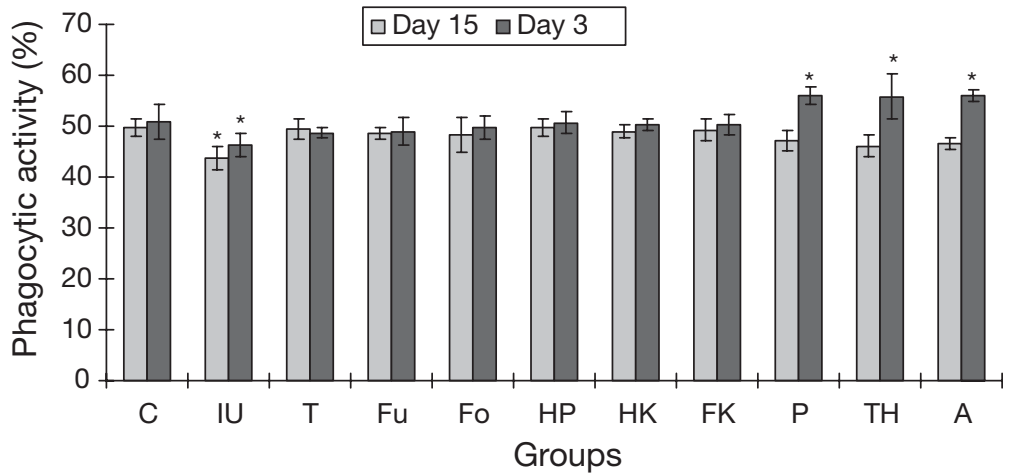

Fig. 1. Carassius auratus. Phagocytic activity of leukocytes from goldfish infected with Aeromonas hydrophila after administration of chemotherapy (T: tetracycline, Fu: furanace, Fo: formalin, HP: hydrogen peroxide), vaccines (HK: heat-killed, FK: formalin-killed) and diets supplemented with immunostimulants (P: probiotics, TH: tri-herbal, A: azadirachtin) on Days 15 and 30 compared with control (C) and infected but untreated (IU) groups.

Values represent the mean $\pm \mathrm{SE}(\mathrm{n}=6)$ of duplicate samples. ${ }^{*} \mathrm{p}<0.05$

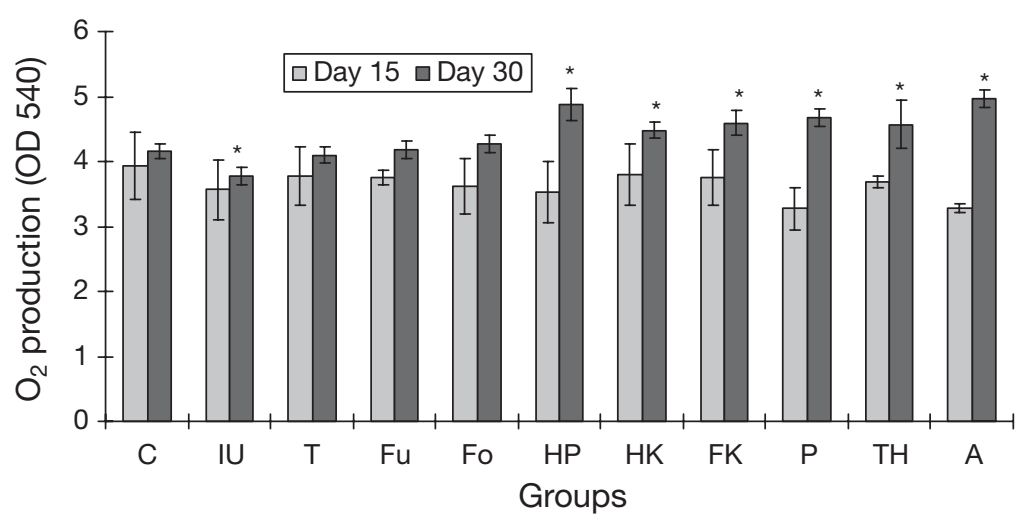

Fig. 2. Carassius auratus. Superoxide anion production by leukocytes of goldfish infected with Aeromonas hydrophila after the various treatments on Days 15 and 30. Abbreviations and statistical information as in Fig. 1 
0.05). However, in fish treated with antibiotics (tetracycline and furanace), chemicals (formalin and hydrogen peroxide) and vaccine (heat-killed), no significant lysozyme activity was found on Day 15 or 30.

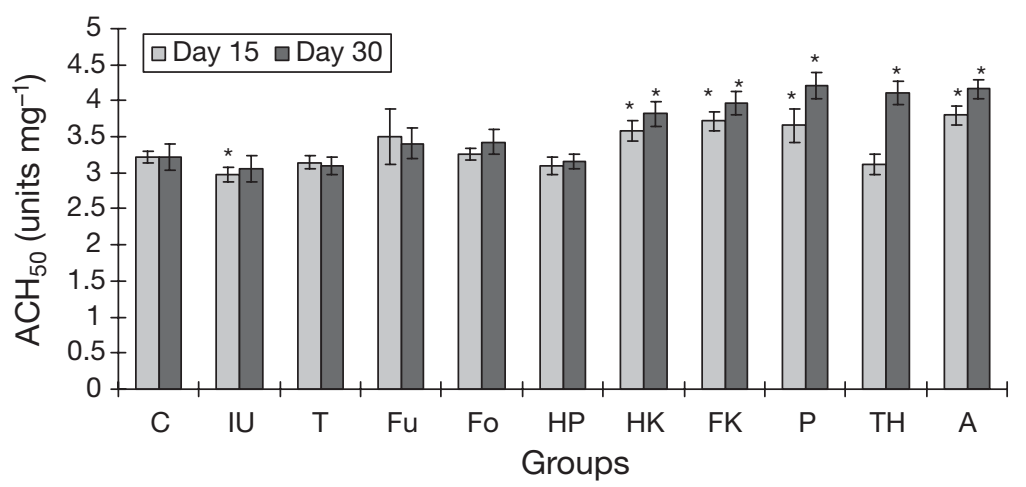

Fig. 3. Carassius auratus. Natural alternative complement activity in goldfish infected with Aeromonas hydrophila after the various treatments on Days 15 and 30. Abbreviations and statistical information as in Fig. 1

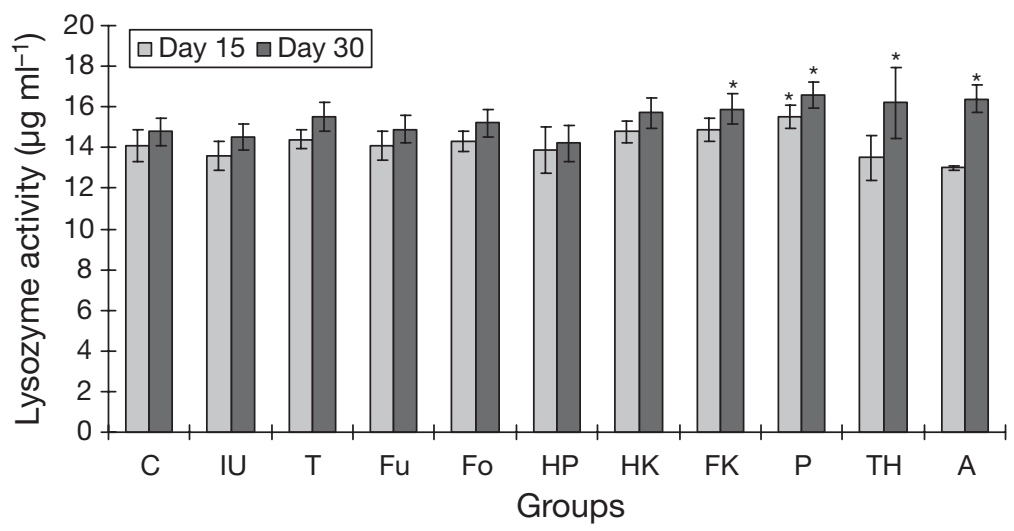

Fig. 4. Carassius auratus. Serum lysozyme activity in goldfish infected with Aeromonas hydrophila after the various treatments on Days 15 and 30 . Abbreviations and statistical information as in Fig. 1

\section{Disease resistance}

No mortality $(0 \%)$ was seen in the groups fed the probiotics- and tri-herbal-supplemented diets (Fig. 5). Among the other infected groups that received treatment, the lowest mortality rates were recorded in the groups given the heat-killed (30\%), formalin-killed (35\%) vaccines and azadirachtin-supplemented diet $(10 \%)$, which thus afforded maximum protection. The cumulative mortality was high in fish treated with antibiotics (tetracycline, 65\% and furanace, $70 \%$ ) and chemicals (formalin, $60 \%$ and hydrogen peroxide, $70 \%$ ) on Day 30. The infected but untreated group had a $95 \%$ mortality rate, and no mortality was seen in the control group.

\section{DISCUSSION}

The nonspecific immune system of fish is the first line of defence against invading pathogens. Enhancement of the immune system seems to be the most promising tool for preventing fish diseases. Natural immunostimulants can protect fish against diseases (Anderson \& Siwicki 1994, Siwicki et al. 1994) and enhance respiratory burst and phagocytic activities in fish (Cuesta et al. 2003). In aquaculture, the use of medicinal herbs (with their low levels of sideeffects) as immunostimulants has received more attention during the last 2 decades. Herb-based immunostimulants can enhance growth and immune responses and/

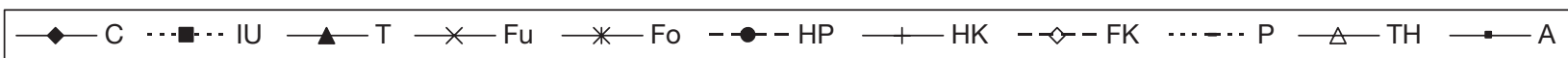

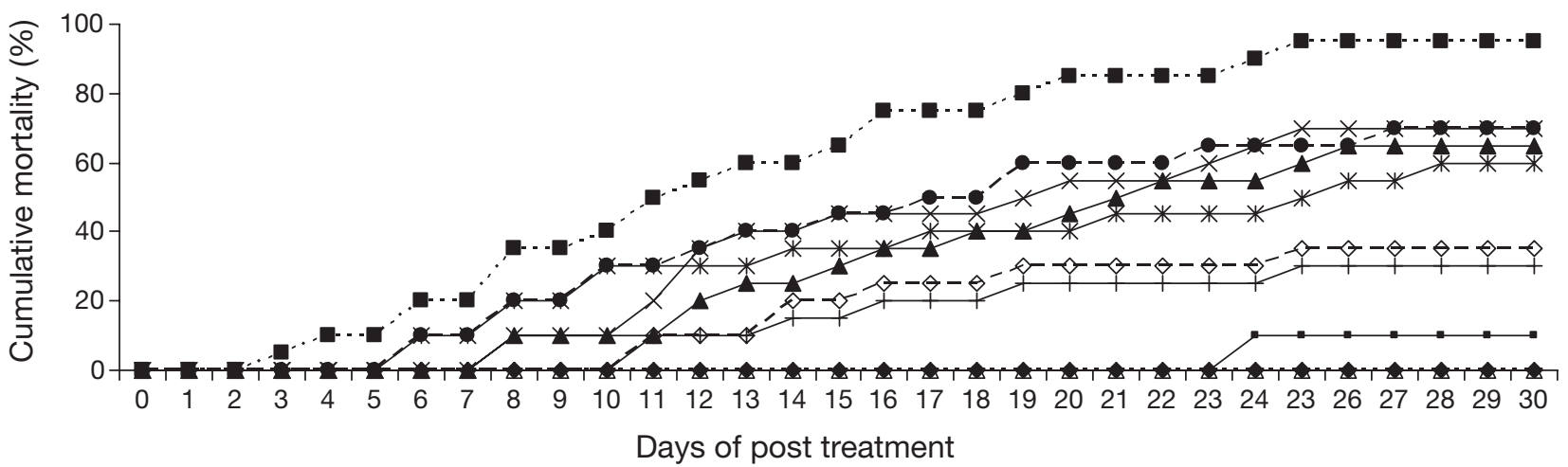

Fig. 5. Carassius auratus. Cumulative mortality rate of goldfish infected with Aeromonas hydrophila after the various treatments during 30 d. Abbreviations as in Fig. 1 
or reduce losses from viral, bacterial and/or parasitic infections in fishes such as carp (Sahu 2004, Sahu et al. 2007). In China, traditional Chinese herbs have been used as immunostimulants for thousands of years (Tan \& Vanitha 2004). These herbs contain many types of active components, such as polysaccharides, alkaloids or flavonoids. The immunostimulating activities of herbal components have been widely studied in mouse cell lines, chicken cell lines and human cell lines (Shan et al. 1999, Cao \& Lin 2003, Lin \& Zhang 2004). The major components of the innate immune system (nonspecific) are macrophages, monocytes, granulocytes and humoral elements such as lysozymes and the complement system (Secombes \& Fletcher 1992, Magnadóttir 2006).

A number of biological and synthetic compounds have been shown to enhance the nonspecific immune system of cultivated fish (Sakai 1999) through modulation of cell surface molecules involved in bacterial uptake by leukocytes (Jeney et al. 1997). Herbal extracts and probiotics (Fuller 1989, Salinas et al. 2005, Kim \& Austin 2006) can also enhance phagocytosis in various fish species (Chen et al. 2003, Dügenci et al. 2003). In the present study, diets supplemented with probiotics, tri-herbals and azadirachtin significantly $(p<0.05)$ enhanced the phagocytic activity of leukocytes $30 \mathrm{~d}$ after goldfish were infected with Aeromonas hydrophila, whereas treatment with antibiotics (tetracycline and furanace), chemicals (formalin and hydrogen peroxide) and heat- and formalin-killed vaccines did not enhance phagocytic activity either on Day 15 or 30 ( $\mathrm{p}>0.05)$. Other researchers have found that vaccines and immunostimulants enhanced the innate (nonspecific) immune response (Newman 1993, Sakai 1999). Immunostimulants can be applied via injection, bathing or orally; the latter seems to be the most practicable (Jeney \& Anderson 1993, Sakai 1999, Yin et al. 2006).

Phagocytes produce toxic oxygen forms during respiratory burst (Neumann et al. 2001), which has been accepted as an accurate parameter to quantify the intensity of a respiratory burst (Secombes 1990). The phagocytic cells might have retained the capacity to produce superoxide anion radicals, which is important for mediating immunity. In the present study, the increase in superoxide anion production from head kidney leukocytes observed after treatment with vaccines and immunostimulant-enriched diets on Day 30 is in agreement with previous studies (Villamil et al. 2002). Feeding of yeast glucan enhanced intracellular superoxide production in large yellow croaker (Ai et al. 2007), rainbow trout (Kim \& Austin 2006) and Indian major carps such as Catla catla, Labeo rohita and Cirrhinus mrigala (John et al. 2002). Intracellular respiratory burst activity was enhanced in large yellow croaker and common carp after feeding with a diet enriched with the Chinese herbs Astragalus membranaceus and Angelica sinensis (Jian \& Wu 2003, 2004).

In the present study, alternative complement activity was significantly $(\mathrm{p}<0.05)$ enhanced in the groups administered vaccines and probiotics-, tri-herbal- and azadirachtin-supplemented diets on Days 15 and 30 compared to control. Complement activity may be one of the most important serum factors since it activates the cellular defences. However, groups treated with antibiotics (tetracycline and furanace) and chemicals (formalin and hydrogen peroxide) did not show enhanced complement activity in the present study, unlike the significantly enhanced complement activity found in crucian carp (Chen et al. 2003), large yellow croaker (Jian \& Wu 2003) and common carp (Jian \& Wu 2004) after feeding with Chinese herbal extracts. In the present study, the significant increase in complement activity observed after administration of vaccines and immunostimulants may imply that the fish were in an immunologically alert state. However, antibiotics and chemicals failed to enhance complement activity.

Compared with the control group, lysozyme activity in the groups given formalin-killed vaccine and probiotics-, tri-herbal- and azadirachtin-supplemented diets was significantly enhanced $(\mathrm{p}<0.05)$ on Day 30 . Mock $\&$ Peters (1990) reported an initial activation of lysozyme activity in stressed rainbow trout followed by impairment and final breakdown of this response. In common carp and large yellow croaker, plasma lysozyme activity was significantly increased after feeding with a mixture of Astragalus membranaceus and Angelica sinensis (Jian \& Wu 2003, 2004). Similar results have been reported in various fish species, e.g. rainbow trout, Indian major carp and Mozambican tilapia (Dey \& Chandra 1995, Logambal \& Michael 2000, Dügenci et al. 2003). In several studies, immunostimulants, vaccines and probiotics enhanced plasma lysozyme activity (Siwicki et al. 1994, Hanif et al. 2005, Kim \& Austin 2006). However, treatment with antibiotics and chemicals failed to enhance lysozyme activity in the present study. An increase in the lysozyme concentration in fish blood can be caused by infections or invasion by foreign material (Fletcher \& White 1973, Siwicki \& Studnicka 1987).

The survival rate of infected fish has been observed to increase after treatment with immunostimulants (Anderson 1992, Sakai 1999), vaccines (Bakopoulos et al. 2003) and probiotics (Brunt et al. 2007). In the present study, after goldfish were challenged with Aeromonas hydrophila, mortality declined in all treated groups. Probiotics- and tri-herbal-supplemented diets had no associated mortality and the azadirachtinenriched feed registered $10 \%$ mortality. Among the 
groups treated with antibiotics and chemicals, mortality was high, ranging from 60 to $70 \%$. In carp fed chitosan and levamisole, mortality was reduced following a challenge with A. hydrophila (Gopalakannan \& Arul 2006). A similar result was reported in large yellow croaker fed glucan and challenged with Vibrio harveyi (Ai et al. 2007).

Administration of probiotics, tri-herbal extract and/or azadirachtin significantly enhanced respiratory burst, phagocytic activity and lysozyme activity in goldfish challenged with Aeromonas hydrophila. These treatments also enhanced the survival rate of infected fish, indicating their possible use as prophylactic and therapeutic agents against bacterial fish diseases, with or without commercial antibiotics and chemicals. However, further investigation into the toxicity, stability and metabolism of immunostimulants and their components must first be undertaken.

Acknowledgements. R.H. is grateful to the Council of Scientific and Industrial Research (CSIR), India for the award of Research Associateship, and the financial assistance through KOSEF Postdoctoral Fellowship and BK 21 program of the Ministry of Education, South Korea, which made this work possible. We are grateful to the UGC-SAP and DST-FIST, Government of India for the facilities made available to support this work.

\section{LITERATURE CITED}

Ahilan B, Shine G, Santhanam R (2004) Influence of probiotics on the growth and gut microbial load of juvenile goldfish (Carassius auratus). Asian Fish Sci 17:271-278

Ai Q, Mai K, Zhang L, Tan B, Zhang W, Xu W, Li H (2007) Effects of dietary $\beta-1,3$-glucan on innate immune response of large yellow croaker, Pseudosciena crocea. Fish Shellfish Immunol 22:394-402

Amar EC, Kiron V, Satoh S, Okamoto N, Watanabe T (2000) Effect of dietary $\beta$-carotene on the immune response of rainbow trout Oncorhynchus mykiss. Fish Sci 66: 1068-1075

Amin NE, Abdallah IS, Elallawy T, Ahmed SM (1985) Motile Aeromonas septicaemia among Tilapia nilotica (Sarotherodon niloticus) in upper Egypt. Fish Pathol 20:93-97

Anderson DP (1992) Immunostimulants, adjuvants and vaccine carriers in fish: applications to aquaculture. Annu Rev Fish Dis 2:281-307

Anderson DP, Siwicki AK (1994) Duration of protection against Aeromonas salmonicida in brook trout immunostimulated with glucan or chitosan by injection or immersion. Prog Fish-Cult 56:258-261

Areerat S (1987) Clarias culture in Thailand. Aquaculture 63: $355-362$

> Azad IS, Shankar KM, Mohan CV, Kalita B (1999) Biofilm vaccine of Aeromonas hydrophila-standardization of dose and duration for oral vaccination of carps. Fish Shellfish Immunol 9:519-528

Bakopoulos V, Volpatti D, Gusmani L, Galeotti M, Adams A, Dimitriadis GJ (2003) Vaccination trials of sea bass, Dicentrarchus labrax (L.), against Photobacterium damsela subsp. piscicida, using novel vaccine mixtures. J Fish Dis 26:77-90
Brunt J, Newaj-Fizul A, Austin B (2007) The development of probiotics for the control of multiple bacterial diseases of rainbow trout, Oncorhynchus mykiss (Walbaum). J Fish Dis 30:573-579

Bryan GW (1984) Pollution due to heavy metals and their compounds. PSZN I: Mar Ecol S3:1289-1431

Cahill MM (1990) Virulence factors in motile Aeromonas species. J Appl Bacteriol 69:1-16

Cao LZ, Lin ZB (2003) Regulatory effect of Ganoderma lucidum polysaccharides on cytotoxic T-lymphocytes induced by dendritic cells in vitro. Acta Pharmacol Sin 24: 321-326

Chabot DJ, Thunne RL (1991) Proteases of the Aeromonas hydrophila complex: identification, characterization and relation to virulence in channel catfish, Ictalurus punctatus (Rafinnesque). J Fish Dis 14:171-183

Chen X, Wu Z, Yin J, Li L (2003) Effects of four species of herbs on immune function of Carassius auratus gibelio. J Fish Sci China 10:36-40 (in Chinese)

$>$ Chu WH (2006) Adjuvant effect of propolis on immunisation by inactivated Aeromonas hydrophila in carp (Carassius auratus gibelio). Fish Shellfish Immunol 21:113-117

> Cuesta A, Esteban MA, Meseguer J (2003) In vitro effect of chitin particles on innate cellular immune system of gilthead seabream (Sparus aurata L.). Fish Shellfish Immunol 15:1-11

> Davis JF, Hayasaka SS (1983) Pathogenic bacteria associated with cultured American eels Anguilla rostrata Le Sueur. J Fish Biol 23:557-564

De Man JC, Rogosa M, Sharpe ME (1960) A medium for the cultivation of lactobacilli. J Appl Bacteriol 23:130-135

Dey RK, Chandra S (1995) Preliminary studies to raise disease resistant seed (fry) of Indian major carp Catla catla (Ham.) through herbal treatment of spawn. Fish Chimes 14:23-25

Dügenci SK, Arda N, Candan A (2003) Some medicinal plants as immunostimulant for fish. J Ethnopharmacol 88:99-106

Ellis AE (1988) General principles of fish vaccination. In: Ellis AE (ed) Fish vaccination. Academic Press, London, p 1-19

Ellis AE (1990) Lysozyme assays. In: Stolen JS, Fletcher TC, Anderson DP, Roberson BS, van Muiswinkel WD (eds) Techniques in fish immunology. SOS Publications, Fair Haven, NJ, p 101-104

Fletcher T, White A (1973) Lysozyme activity in the plaice (Pleuronectes platessa L.). Experientia 29:1283-1285

> Fuller R (1989) Probiotics in man and animals. J Appl Bacteriol 66:365-378

Gopalakannan A, Arul V (2006) Immunomodulatory effects of dietary intake of chitin, chitosan and levamisole on the immune system of Cyprinus carpio and control of Aeromonas hydrophila infection in ponds. Aquaculture 255: 179-187

> Hanif A, Bakopoulos V, Leonardos I, Dimitriadis GJ (2005) The effect of sea bream (Sparus aurata) broodstock and larval vaccination on the susceptibility by Photobacterium damsela subsp. piscicida and on the humoral immune parameters. Fish Shellfish Immunol 19:345-361

Harikrishnan R, Balasundaram C (2005) Antimicrobial activity of medicinal herbs in vitro against fish pathogen, Aeromonas hydrophila. Fish Pathol 40:187-189

Harikrishnan R, Nisha Rani M, Balasundaram C (2003) Hematological and biochemical parameters in common carp, Cyprinus carpio, following herbal treatment for Aeromonas hydrophila infection. Aquaculture 221:41-50

> Harikrishnan R, Balasundaram C, Bhuvaneswari R (2005) Restorative effect of Azadirachta indica aqueous leaf extract dip treatment on haematological parameter changes in Cyprinus carpio (L.) experimentally infected 
with Aphanomyces invadans fungus. J Appl Ichthyol 21: $410-413$

Harikrishnan R, Balasundaram C, Moon YG, Kim MC, Kim JS, Heo MS (2009a) Use of herbal concoction in the therapy of goldfish (Carassius auratus) infected with Aeromonas hydrophila. Bull Vet Inst Pulawy 53:27-36

- Harikrishnan R, Balasundaram C, Kim MC, Kim JS, Han YJ, Heo MS (2009b) Innate immune response and disease resistance in Carassius auratus by triherbal solvent extracts. Fish Shellfish Immunol 27:508-515

Jeney G, Anderson DP (1993) An in vitro technique for surveying immunostimulants in fish. Aquaculture 112: 283-287

> Jeney G, Galeotti M, Volpatti D, Jeney Z, Anderson DP (1997) Prevention of stress in rainbow trout (Oncorhynchus mykiss) fed diets containing different doses of glucan. Aquaculture 154:1-15

> Jian J, Wu Z (2003) Effects of traditional Chinese medicine on nonspecific immunity and disease resistance of large yellow croaker, Pseudosciaena crocea (Richardson). Aquaculture 218:1-9

> Jian J, Wu Z (2004) Influences of traditional Chinese medicine on non-specific immunity of Jian carp (Cyprinus carpio var. Jian). Fish Shellfish Immunol 16:185-191

John MB, Chandran MR, Aruna BV, Anbarasu K (2002) Production of superoxide anion by head-kidney leukocytes of Indian major carps immunised with bacterins of Aeromonas hydrophila. Fish Shellfish Immunol 12:201-207

> Joseph SW, Carnahan A (1994) The isolation, identification, and systematics of the motile Aeromonas species. Annu Rev Fish Dis 4:315-343

> Jung HH, Sim DS, Park MS, Jo QT, Kim Y (2003) Effects of formalin on haematological and blood chemistry in olive flounder, Paralichthys olivaceus (Temminck et Schlegel). Aquacult Res 34:1269-1275

Karunasagar I, Ali A, Otta SK, Karunasagar I (1997) Immunization with bacterial antigens: infections with motile aeromonads. In: Gudding R, Lillehaug A, Midtlyng PJ, Brown F (eds) Fish vaccinology. Developments in biological standardization, Vol 90. Karger, Basel, p 135-141

Kim DH, Austin B (2006) Innate immune responses in rainbow trout (Oncorhynchus mykiss, Walbaum) induced by probiotics. Fish Shellfish Immunol 21:513-524

Lin ZB, Zhang HN (2004) Anti-tumor and immunoregulatory activities of Ganoderma lucidum and its possible mechanisms. Acta Pharmacol Sin 25:1387-1395

Logambal SM, Michael RD (2000) Immunostimulatory effect of azadirachtin in Oreochromis mossambicus (Peters). Indian J Exp Biol 38:1092-1096

Logambal SM, Michael RD (2001) Azadirachtin-an immunostimulant for Oreochromis mossambicus (Peters). J Aquacult Trop 16:339-347

Magnadóttir B (2006) Innate immunity of fish (overview). Fish Shellfish Immunol 20:137-151

> Mayer AMS, Hamann MT (2002) Marine pharmacology in 1999: compounds with antibacterial, anticoagulant, antifungal, anthelmintic, anti-inflammatory, antiplatelet, antiprotozoal and antiviral activities affecting the cardiovascular, endocrine, immune and nervous systems and other miscellaneous mechanisms of action. Comp Biochem Physiol C 132:315-339

> Mitra CR, Garg HS, Pandey GN (1971) Constituents of Azadirachta indica. Part III. Identification of nimbidic acid and nimbidinin from Azadirachta indica. Phytochemistry 10:857-864

> Möck A, Peters G (1990) Lysozyme activity in rainbow trout, Oncorhynchus mykiss (Walbaum), stressed by handling, transport and water pollution. J Fish Biol 37:873-885

Neumann NF, Stafford JL, Barreda D, Ainsworth AJ, Belosevic $M$ (2001) Antimicrobial mechanisms of fish phagocytes and their role in host defence. Dev Comp Immunol 25: 807-825

$>$ Newman SG (1993) Bacterial vaccines for fish. Annu Rev Fish Dis 3:145-185

Newman DJ, Cragg GM, Snader KM (2003) Natural products as sources of new drugs over the period 1981-2002. J Nat Prod 66:1022-1037

Noga E (1996) Fish disease: diagnosis and treatment. MosbyYear Book, St. Louis, MO, p 367

> Paniagua C, Rivero O, Anguita J, Naharro G (1990) Pathogenicity factors and virulence for rainbow trout (Salmo gairdneri) or motile Aeromonas spp. isolated from a river. J Clin Microbiol 28:350-355

Rahman MH, Kusuda R, Kawai K (1997) Virulence of starved Aeromonas hydrophila to cyprinid fish. Fish Pathol 32: 163-168

Rath RK (2000) Freshwater aquaculture, 2nd edn. Scientific Publishers (India), Jodhpur

Rojanapo W, Suwanno S, Somaree R, Glinsukon T, Thebtaranonth Y (1985) Mutagenic and antibacterial activity testing of nimbolide and nimbic acid. J Sci Soc Thailand (ScienceAsia) 11:177-181

Rowley AF (1990) Collection, separation and identification of fish leucocytes. In: Stolen JS, Fletcher TC, Anderson DP, Roberson BS, van Muiswinkel WD (eds) Techniques in fish immunology, fish immunology technical communications. SOS Publications, Fair Haven, NJ, p 113-136

> Russo R, Curtis EW, Yanong RPE (2007) Preliminary investigations of hydrogen peroxide treatment of selected ornamental fishes and efficacy against external bacteria and parasites in green swordtails. J Aquat Anim Health 19: $121-127$

Sahu S (2004) Antibacterial activity of plant extracts on fish microbial pathogens. MFSc thesis, Central Institute of Freshwater Aquaculture (CIFA), Kausalyaganga, Bhubaneswar, India

Sahu S, Das BK, Mishra BK, Pradhan J, Sarangi N (2007) Effect of Allium sativum on the immunity and survival of Labeo rohita infected with Aeromonas hydrophila. J Appl Ichthyol 23:80-86

Sakai M (1999) Current research status of fish immunostimulants. Aquaculture 172:63-92

Salinas I, Cuesta A, Esteban MA, Meseguer J (2005) Dietary administration of Lactobacillus delbrüecki and Bacillus subtilis, single or combined, on gilthead seabream cellular innate immune responses. Fish Shellfish Immunol 19: $67-77$

Secombes SJ (1990) Isolation of salmonid macrophages and analysis of their killing activity. In: Stolen JS, Fletcher TC, Anderson DP, Roberson BS, van Muiswinkel WD (eds) Techniques in fish immunology. SOS Publications, Fair Haven, NJ, p 137-154

Secombes CJ, Fletcher TC (1992) The role of phagocytes in the protective mechanisms of fish. Annu Rev Fish Dis 2: $53-71$

Seeley KR, Gillespie PD, Weeks BA (1990) A simple technique for the rapid spectrophotometric determination of phagocytosis by fish macrophages. Mar Environ Res 30:37-41

Shan BE, Yoshida Y, Sugiura T, Yamashita U (1999) Stimulating activity of Chinese medicinal herbs on human lymphocytes in vitro. Int J Immunopharmacol 21:149-159

Shao ZJ (2001) Aquaculture pharmaceuticals and biologicals: current perspectives and future possibilities. Adv Drug Deliv Rev 50:229-243 
Shotts EB, Rimler R (1973) Medium for the isolation of Aeromonas hydrophila. Appl Microbiol 26:550-553

Siwicki AK, Studnicka M (1987) The phagocytic activity of neutrophils and serum lysozyme activity in experimentally infected carp, Cyprinus carpio L. J Fish Biol 31:57-60

Siwicki AK, Anderson DP, Rumsey GL (1994) Dietary intake of immunostimulants by rainbow trout affects non-specific immunity and protection against furunculosis. Vet Immunol Immunopathol 41:125-139

Tan BKH, Vanitha J (2004) Immunomodulatory and antimicrobial effect of some traditional Chinese medicinal herbs. Curr Med Chem 11:1423-1430

Tzianabos AO (2000) Polysaccharide immunomodulators as therapeutic agents: structural aspects and biologic function. Clin Microbiol Rev 13:523-533

Editorial responsibility: David Bruno,

Aberdeen, UK
Villamil L, Tafalla C, Figueras A, Novoa B (2002) Evaluation of immunomodulatory effects of lactic acid bacteria in Turbot (Scophthalmus maximus). Clin Diagn Lab Immunol 9: 1318-1323

Yadav M, Indira G, Ansary A (1992) Cytotoxin elaboration by Aeromonas hydrophila isolated from fish with epizootic ulcerative syndrome. J Fish Dis 15:183-189

Yano T (1992) Assay of hemolytic complement activity. In: Stolen JS, Fletcher TC, Anderson DP, Hattari SC, Rowley AF (eds) Techniques in fish immunology. SOS Publications, Fair Haven, NJ, p 131-141

Yin G, Jeney G, Rácz T, Xu P, Jun X, Jeney Z (2006) Effect of two Chinese herbs (Astragalus radix and Scutellaria radix) on non-specific immune response of tilapia, Oreochromis niloticus. Aquaculture 253:39-47

Submitted: June 10, 2009; Accepted: September 11, 2009 Proofs received from author(s): December 4, 2009 